\title{
CORRECTION
}

View Article Online

View Journal I View Issue

W) Check for updates

Cite this: J. Mater. Chem. A, 2018, 6, 16274

DOI: $10.1039 / \mathrm{c} 8 \mathrm{ta} 90188 \mathrm{k}$

www.rsc.org/MaterialsA

\section{Correction: Nanofiltration membranes with cellulose nanocrystals as an interlayer for unprecedented performance}

\author{
Jing-Jing Wang, Hao-Cheng Yang, Ming-Bang Wu, Xi Zhang and Zhi-Kang Xu* \\ Correction for 'Nanofiltration membranes with cellulose nanocrystals as an interlayer for unprecedented \\ performance' by Jing-Jing Wang et al., J. Mater. Chem. A, 2017, 5, 16289-16295.
}

The authors regret the following errors in the quoted concentration and coating density of cellulose nanocrystals on page 16290 in the published article:

The sentence "The final product was ultrasonically dispersed in water with a concentration of $1.2 \mathrm{~g} \mathrm{~L}^{-1}$ before use" should instead read as follows: "The final product was ultrasonically dispersed in water with a concentration of $0.5 \mathrm{~g} \mathrm{~L}^{-1}$ before use".

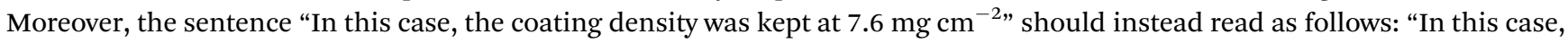

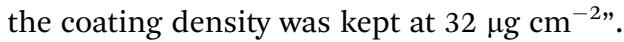

The Royal Society of Chemistry apologises for these errors and any consequent inconvenience to authors and readers. 